\title{
Systemic resilience: principles and processes for a science of change in contexts of adversity
}

\author{
Michael Ungar ${ }^{l}$
}

\begin{abstract}
Despite the increasing popularity of discussions of resilience in disciplines as diverse as ecology, psychology, economics, architecture, and genetics (among many others), researchers still lack a conceptual model to explain how the resilience of one system relates to the resilience of other cooccurring systems. Models that explain resilience within a single system are more robust and better studied. Although some researchers argue that both ontological and epistemological weaknesses prevent such an integrated model from being developed (the incommensurability hypothesis), others have carried out metasyntheses using techniques like network citation analysis to identify common principles and processes that are associated with resilience across disciplines. Although useful, metasyntheses have yet to identify sufficient commonalities across bodies of research to account for a single model of resilience. This paper adapts methods used for the thematic synthesis of qualitative data to critically analyze metasyntheses of resilience and identify principles that explain patterns of resilience of different systems (biological, psychological, social, cultural, economic, legal, communication, and ecological systems are all considered). Sixteen purposefully selected published syntheses were reviewed, along with dozens of other supporting peer-reviewed articles and book chapters, supplemented by consultations with knowledge experts. Seven common principles across systems were identified. These include: (1) resilience occurs in contexts of adversity; (2) resilience is a process; (3) there are trade-offs between systems when a system experiences resilience; (4) a resilient system is open, dynamic, and complex; (5) a resilient system promotes connectivity; (6) a resilient system demonstrates experimentation and learning; and (7) a resilient system includes diversity, redundancy, and participation. Where evidence refutes a principle, discordant findings are highlighted. Together, these principles account for resilience as a sequence of systemic interdependent interactions through which actors (whether persons, organisms, or ecosystems) secure the resources required for sustainability in stressed environments.
\end{abstract}

Key Words: common principles; disaster management; ecology; psychology; resilience; social-ecological systems; systemic

\section{INTRODUCTION}

In disciplines as diverse as genetics, psychology, sociology, disaster management, public health, urban development, and environmental science, there is movement away from research on the factors that produce disease and dysfunction to analyses of capacity building, patterns of self-organization, adaption, and in the case of human psychology, underlying protective and promotive processes that contribute to the resilience of complex systems. Broadly understood across all these systems, resilience is the capacity of a system to anticipate, adapt, and reorganize itself under conditions of adversity in ways that promote and sustain its successful functioning (in human terms, its wellbeing) (Gotts 2007, Folke et al. 2010, Ungar 2011, Masten 2014). That capacity, though, is seldom a trait of the system itself, but instead the result of facilitative interactions with cooccurring, subordinate, and supraordinate systems that make it possible for a system or its parts to function well during and after a disturbance.

Not surprisingly, this paradigm shift from a focus on problems to solutions has opened a Pandora's box of ontological and epistemological challenges that include definitional ambiguity, inconsistent measurement, and narrowly described theories that account for resilience in one discipline at one systemic level but not others. Even disciplines relatively close to one another are struggling. For example, studies of community sustainability and urban design are finding it difficult to integrate resilience thinking because of heterogeneity in definitions and a lack of consistency in what is measured and how (Leichenko 2011). Where consensus between disciplines has been reached (e.g., disaster management and psychology have identified a similar set of factors associated with individual and collective resilience such as continuity of relationships and the need to return to school or work quickly after being displaced [Abramson et al. 2008, Cutter et al. 2008a, $b]$ ), researchers have still remained largely in their own disciplinary silos, with few publications identifying cooccurring principles to guide interventions at multiple systemic levels. For example, a study documenting the resilience of adolescent-age Syrian refugees in Jordan showed that young people did best when they measured high on psychological resilience and lived in resilient communities that provided refugees with the infrastructure they needed to thrive (Panter-Brick et al. 2017).

This tension between shared disciplinary diversity and shared principles is well illustrated by the citation network analysis conducted by Baggio et al. (2015) that showed that resilience is both a boundary and bridging concept. As a boundary concept, resilience is well defined within disciplines, usually with reference to a few seminal pieces of writing from other disciplines to stimulate theory development. In rare cases, resilience is also a bridging concept, helping disciplines to identify patterns of behavior among different systems that share characteristics associated with resilience as it is defined by more than one discipline. For example, Brown (2016) explores how resilience in the field of international development can both influence the psychological resilience of individuals and make economic systems more sustainable at the same time. Even though the number of papers on resilience has increased exponentially over the past 30 years (Xue et al. 2018), very few publications offer conceptual bridges between research on resilience across systems. 
This purpose of this paper, then, is to build conceptual bridges between disciplines and identify a common set of principles to explain resilience among cooccurring systems. To accomplish this, a qualitative approach to the thematic synthesis of findings from a purposeful sample of published syntheses of studies of resilience has been used. Many of these existing syntheses have deepened our understanding of how the term resilience is conceptualized in diverse bodies of literature. For example, $\mathrm{Xu}$ and Kajikawa (2017) have made a remarkable contribution to the field of resilience by identifying ten clusters of resilience research drawn from a wide selection of disciplines ranging from materials science to brain science and ecology. They explored all ten with regard to four topic areas: conceptions, characteristics, influencing factors, and intervention strategies. Their comprehensive network citation analysis identified the major themes being discussed in the literature and the complexity of how resilience is understood and applied. Other syntheses have approached the diversity of resilience research in very different ways with equally long lists of factors. For example, Bousquet et al. (2016) summarized more than 600 presentations from the Resilience 2014 conference held in Montpellier, France, identifying common themes related to theory and measurement. The present work is not meant to replicate these or any other synthesis of the research but to build on the results of these quantitative approaches to arrive at a set of unifying principles that account for the phenomenon of resilience across disciplines and systems.

\section{A CRITICAL READ OF THE RESILIENCE LITERATURE}

The study of resilience shifts the focus of research to processes of recovery, adaptation, or transformation when a system is under stress. For example, Masten (2014), a psychologist, has taken a much broader systems view of resilience than is typical of her field. She writes:

\section{Resilience can be broadly defined as the capacity of a dynamic system to adapt successfully to disturbances that threaten system function, viability, or development. The concept can be applied to systems of many kinds at many interacting levels, both living and nonliving, such as a microorganism, a child, a family, a security system, an economy, a forest, or the global climate. (Masten 2014:6)}

Similarly, researchers studying community and disaster resilience have broadened their definitions to consider intersecting systems that shape and construct communities, framing these more from a human-in-context perspective (Cutter et al. 2008a, b). The models they propose, such as that by Cutter, emphasize a placebased approach to resilience focused on the ways in which "human systems, environmental systems, and the built environment interact to produce antecedent conditions which contain both inherent vulnerabilities as well as inherent resilience" (Cutter 2014:66). Likewise, Norris and her colleagues (Norris et al. 2008) frame resilience as networked capacities that support preparedness, response, and adaptation to extreme climatic and social events. Still others in the field adopt a social capital-based approach that identifies a range of different capitals (e.g., social, economic, human, political, natural, and built) that link resilience to economics, power, and adaptive learning (Cox and Hamlen 2015). Community resilience, therefore, refers to the ability of a social group (a complex system with multiple functions) to anticipate and adapt to change using its own inherent strengths and characteristics to absorb the impact of a disturbance (e.g., disaster event) and to participate in the human, social, economic, political, and cultural processes that support the system in reorganizing and adapting to changes, all the while learning from the event (Cutter et al. 2008a, b, United Nations International Strategy for Disaster Reduction 2009).

When considering resilience in communities, however, an analysis of power relations (historic and present) must also be made. The division of structural power shapes the capacity of any individual or group accessing and employing resources (Abramson et al. 2010, Fordham et al. 2013). Other systems are also affected by power, although that power may be less evident as in discursive power in psychology (the power to influence whether specific outcomes are socially desirable [Ungar 2004, Harris et al. 2017]) or, in the case of ecological systems, be nonagentic. It is impossible without human judgment to discern if one regime is better or worse for an ecosystem than another.

As would be expected, environmental scientists are also theorizing resilience as a complex process that accounts for interactions within and between systems that create new regimes of behavior to accommodate perturbations in the environment (Folke 2006). Following in the tradition of the Resilience Alliance, and building on C.S. Holling's (1973) critically important work:

Ecological resilience refers to the magnitude of
disturbance that a system can absorb before shifting to
an alternate regime or system state. Ecological resilience
thus assumes that a system has multiple alternate
equilibria and focuses on the capacity of a system to
maintain, including through reorganization, its essential
structure and function when confronted with shocks. This
capacity for self-organization has not always been clearly
defined, but it is a key aspect of complex adaptive systems
that enables them to regenerate and transform. (Quinlan
et al. 2016:2)

As researchers come to understand ecological resilience better, a growing number of ecologists are shifting their focus to the resilience of social-ecological systems to account for the inclusion of human-made stressors on ecological systems and the way different plant and animal regimes are more or less adapted to the needs of the people who interact with them (Berkes and Folke 1998, Resilience Alliance 2010, Biggs et al. 2012, Brown 2016, Quinlan et al. 2016). This exploration of social-ecological system recovery, adaptation, and transformation processes (e.g., protective processes that create system-wide resilience) has shown empirical support for a humans-in-nature perspective (Carpenter et al. 1999, 2001, Berkes et al. 2003, Folke 2006, Rocha et al. 2015). It has also provided a way of understanding resilience that aligns well with the properties of complex adaptive systems such as selforganization and emergent behavior (Holling 1986, Levin 1998) and responds to the inclusion of social dynamics among humans and interactions among system components across scales (e.g., spatial scales, temporal scales, levels of governance, etc.) (Gunderson et al. 1995, Gunderson and Holling 2002, Walker and Meyers 2004, Rocha et al. 2015). Furthermore, socialecological systems researchers are incorporating multiple knowledge systems such as indigenous ways of knowing to deepen our collective understanding of resilience in different contexts (Tengö et al. 2014). By way of illustration, a study of access to 
wild foods among indigenous communities in Alaska showed that the resilience of natural ecosystems (including the health of wild herds) is only one of several systems that must function optimally if people are to avoid food scarcity (Baggio et al. 2016). The study found that changes to the way people shared food between households had a much greater influence on the community's robustness than changes in the availability and harvesting of wild food resources.

The example suggests that not only is the resilience of one system potentially a catalyst for the resilience of other cooccurring systems, but that there may also be principles that explain resilience at multiple levels that can help to model these interactions. For example, just as families that are mutually dependent are more resilient, the same principle can be applied to animal herds that, when functioning as a mutually dependent system of individual animals, are more likely to survive. Although there may be trade-offs to resilience (communities can become insular if they only rely on their small number of members, and herds can be weakened without genetic diversity), it is still possible to discern patterns to coping under stress shared by different parts (e.g., scales) of a human-wild food system or other socialecological system. Although to differing degrees, biological, psychological, community, and social-ecological systems theories of resilience all explain the construct in ways that consider human-environment (natural and built) interactions. Indeed, all theories of resilience recognize the environment as both a resilience-promoting catalyst for change as well as a potential resilience-diminishing factor (Kofinas et al. 2013, Carson and Peterson 2016).

\section{THE LIMITS OF CURRENT SYNTHESES OF RESILIENCE RESEARCH}

Efforts to use metaanalyses to identify commonalities and differences in how resilience is described across disciplines have yet to provide a comprehensive model of resilience that explains (1) common principles across disciplines at different systemic levels (e.g., whether similar principles can be observed at biological, psychological, social, economic, and environmental scales), and (2) the degree of interdependence of resilience processes and traits when they are characteristics of multiple cooccurring systems. The syntheses that do exist largely explain resilience from a single disciplinary perspective, which often conflicts with findings in another area of study.

For example, there are distinct differences that have yet to be resolved in descriptions of psychological resilience and the resilience of social-ecological systems despite many syntheses of the literature. Among the most important of these differences are, first, that studies of social-ecological systems tend to see resilience as the capacity of a system, closer to the description of a trait than a process (Gunderson and Holling 2002, Quinlan et al. 2016). Psychologists, social workers, and other mental health professionals, on the other hand, abandoned descriptions of resilience as a trait decades ago and now describe resilience most often as a process (Rutter 1987, Ungar 2011, Masten 2014). This difference between the disciplines has become somewhat blurred as social-ecological systems researchers like Folke (2006) have shown interest in the structure and processes associated with nested adaptive cycles across scales.
Second, studies of social-ecological systems tend to characterize the resilience of any one system as a trade-off against the resilience of another system (Berkes and Folke 1998, Biggs et al. 2015). No one regime is seen as preferred, only of benefit to one or more subsystems. This time, it is the mental health professionals writing about resilience that are in the minority. The concept of tradeoffs can be found in many disciplines, although it appears to be problematic for fields like psychology, psychiatry, and other allied professions. These disciplines prefer an approach to resilience that privileges one set of predetermined "positive" developmental outcomes such as a primary attachment with a caregiver or contribution to one's community as outcomes associated with resilience in stressed social environments (Prince-Embury 2013). There is, however, discord among mental health professionals who argue that differences in power between systems and stakeholders result in the resilience of some systems being labeled as more desirable than others (e.g., a fascist regime can be more stable than a fledgling democracy, although democracy is more socially desirable in many contexts). For example, Ungar (2015c) describes seven different ways that family resilience can be shown, with four of these patterns socially desirable (recovery, nonaffected, minimal impact, and posttraumatic growth), and three socially undesirable (avoidant, hidden, and maladaptive). Ungar's argument is that the desirability of each pattern of coping depends on the resources available to the family and that more desirable behaviors can only occur when other systems facilitate access to the supports families need to do well. Deciding which experience of resilience is best is always negotiated, with the family's experience of resilience sometimes coming at the expense of a community's functioning (e.g., a family's criminal behavior may make them more financially stable and held in higher regard by peers despite the negative impact on their victims and increased demands on services such as policing). Postmodern interpretations of resilience such as this support the position that patterns of resilience that are perceived as negative can still be functional if the resources required to engage in socially just behavior are unavailable.

It is not uncommon, for example, to see studies of psychological resilience that describe family or school interventions to improve a child's self-regulation (Cadimaa et al. 2016) while ignoring other aspects of the various systems that must be transformed to make individual-level change sustainable (e.g., decreasing exposure to toxic chemicals that disrupt human neurocognitive development; political systems that fund school mental health programs; community-level stressors like violence and overcrowding that contribute to emotional dysregulation). Similarly, many studies of community resilience after a disaster (Cutter 2016) fail to incorporate an analysis of power, thereby sidestepping the question of "resilience to what, and for whom." In fields like economics and sociology, these power dynamics are more overt, with attention paid to the rigidity of systems that resist change, power asymmetries, and who has the most influence over social policy (Robards et al. 2011). Whereas some have suggested we stop studying resilience across systems and accept a plurality of perspectives without common ground (the incommensurability hypothesis [Olsson et al. 2015]), it is possible to identify a set of common principles and processes that can account for resilience across multiple systems simultaneously and the trade-offs that are 
inevitable when systems compete for resources. The systemic and multilevel approach that is advocated for in this paper addresses concerns regarding the lack of common principles to understand nuanced differences between theories of environmental (natural and built) and human (biological, psychological and social) resilience.

The irony of metasyntheses across disciplines is that most of the important advances to our understanding of resilience occurred through reflection on findings from a few important studies rather than exhaustive literature reviews using large databases and narrow selection criteria. For example, Biggs et al. (2012, 2015) identified seven principles for services based on qualitative methods that included a "mock court" where proposed principles were put on trial to see if they were empirically sound and a modified Delphi survey of experts. Likewise, the most influential model of family resilience, developed by Walsh (2016), was based largely on qualitative work with a small number of families in Chicago. In each case, critical review of common themes emerging from practice were synthesized into lists of principles that explained the phenomenon under study. These discipline-specific efforts contrast with metaanalysis of research across many different disciplines, which has generated "super" lists of principles for resilience but left researchers with little guidance as to how the resilience of different systems at different scales is interrelated. As Quinlan and her colleagues explain, reductionistic efforts to find common metrics or simplify complexity are not always recommended unless they align with definitions, are contextually relevant, and account for system dynamics (Quinlan et al. 2016). To reach that level of description of resilience, new methods will be needed that support critical reflection and theory innovation.

\section{METHOD}

To synthesize and interpret multiple lists of principles found in the resilience literature across disciplines, qualitative thematic synthesis (commonly used to conduct metaanalysis of qualitative data) (Thomas and Harden 2008, Snilstveit et al. 2012) was used to identify where there is conceptual saturation of principles rather than statistical significance (Saini and Shlonsky 2012). The search for common principles is, arguably, well suited to qualitative inquiry. There were three steps to the methodology: selection of published papers, meetings with experts, and analysis of repeating themes (the principles) found in the selected literature.

\section{Step one}

The selection of the primary documents (published papers) was purposeful, seeking as much conceptual heterogeneity as possible, including negative case examples. It was not important to locate every relevant article, only to ensure that the ideas represented in each discipline-specific cluster of papers were captured in the synthesis of themes. Although the list of papers selected for this review is far from exhaustive (see $\mathrm{Xu}$ and Kajikawa for a more complete citation network), Thomas and Harden (2008) argue in their description of qualitative thematic synthesis that "It may not be necessary to locate every available study because, for example, the results of a conceptual synthesis will not change if ten rather than five studies contain the same concept, but will depend on the range of concepts found in the studies."

\section{Step two}

To achieve sufficient heterogeneity in the sampling of the literature and interpretation of the principles, a series of meetings with knowledge experts from different disciplines, themselves selected through a snowball sampling technique, identified pieces of writing that were perceived as influential in each discipline where the term resilience has been used. The first round of article and book selection originated with a core group of five experts who came together with the purpose of developing a study to explore resilience across biological, psychological, family, community, and ecological systems in communities affected by oil and gas production and climate change. That project, now funded, has been a catalyst for operationalizing resilience across disciplines such as genetics, psychology, community disaster management, and environmental science. A second significant event was the bringing together of 20 international scholars from diverse disciplines with a record of publication related to the concept of resilience. Individuals were identified using three techniques. (1) Invitations were extended to scholars who had produced high profile publications or delivered keynotes at conferences and meetings. (2) Where there was no apparent leader in a particular field of resilience known to the experts who were consulted, such as in the areas of economics and architecture, a search of publications using the search terms "resilience" and the discipline was conducted using Google Scholar and a university search engine with access to multiple databases. Authors whose work appeared in the top ten search items and whose publications showed a systems perspective were invited to participate in faceto-face meetings. (3) A third source of papers came from the anonymous reviewers who provided comments on previous versions of this article.

For a paper to be included in the synthesis, a number of selection criteria were used. First, papers had to be from a scholarly source (a peer-reviewed journal or academic press for books). Although in some cases lay summaries of academic articles were read, original sources are referenced for the purposes of this review. Second, papers had to include a list of principles that were based on studies of resilience. Third, papers had to be recognized as influential, either by being identified by one or more key informants or by their position in online searches. Although far from exhaustive, lists of principles tended to quickly reach saturation and refer back to a common set of papers. For example, psychologists refer to Masten's (2014) work; researchers in the field of social-ecological systems refer to Folke (2006) and Biggs et al. (2015).

\section{Step three}

To analyze these qualitative data (in this case, principles drawn from disciplinarily diverse sources), three stages of analysis were used based on recommendations from Thomas and Harden (2008): (1) a detailed reading of each text and recording of the principles each paper identified, as well as review of minutes from meetings with experts; (2) the drawing together of similar principles into a comprehensive list; and (3) the development of analytic themes that synthesize principles into an abbreviated list of concepts that capture the diversity of perspectives on resilience. This process is by its nature controversial as it is less transparent than statistical analysis (Dixon-Woods et al. 2006, Barnett-Page and Thomas 2009). The purpose in qualitative research is not, however, to generalize, but to demonstrate that the bias of those 
Table 1. Syntheses and metasyntheses of the resilience literature: a purposeful sample, by date and focal system

\begin{tabular}{|c|c|c|}
\hline Author & Focal System(s) & Principles \\
\hline \multicolumn{3}{|c|}{ Xu and Kajikawa 2017} \\
\hline & $\begin{array}{l}\text { Multiple systems arranged in ten clusters: psychology and } \\
\text { social science, social-ecological systems and management, } \\
\text { ecological and environmental sciences, business systems }\end{array}$ & $\begin{array}{l}\text { Characteristics of resilient systems: flexibility, redundancy, diversity, and } \\
\text { connectedness }\end{array}$ \\
\hline & $\begin{array}{l}\text { and engineering, telecommunication systems, psychiatry } \\
\text { and brain science, water systems engineering, livestock and } \\
\text { animal health, marine science and fishery, and biological } \\
\text { and material sciences }\end{array}$ & $\begin{array}{l}\text { Systemic responses to disturbance: recovery, stability, adaptability, } \\
\text { transformability, vulnerability, robustness, resistance, and elasticity }\end{array}$ \\
\hline \multicolumn{3}{|c|}{ Bousquet et al. 2015} \\
\hline & Social ecological systems & Four explanatory elements of change: power, incentives, system, adaptation \\
\hline \multicolumn{3}{|c|}{ Ostrom 2009} \\
\hline \multirow{2}{*}{\multicolumn{2}{|c|}{ Social ecological systems }} & $\begin{array}{l}\text { Four first-level core subsystems of a social ecological system: resource systems, } \\
\text { resource units, governance systems, and users }\end{array}$ \\
\hline & & $\begin{array}{l}\text { Ten second-level variables are named that are likely to influence the capacity of } \\
\text { users of a system to self-organize: size of resource system, productivity of } \\
\text { system, predictability of system dynamics, resource unit mobility, collective- } \\
\text { choice rules, number of users, leadership/entrepreneurship, norms/social } \\
\text { capital, knowledge of SES/mental models, importance of resource }\end{array}$ \\
\hline \multicolumn{3}{|r|}{ 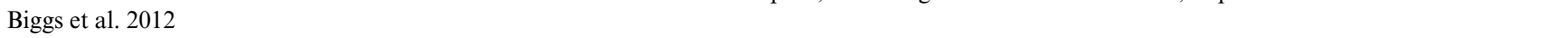 } \\
\hline & Ecosystem services & $\begin{array}{l}\text { Seven policy relevant principles to enhance resilience of ecosystem services: } \\
\text { maintain diversity and redundancy, manage connectivity, manage slow } \\
\text { variables and feedbacks, foster an understanding of social ecological systems as } \\
\text { complex adaptive systems, encourage learning and experimentation, broaden } \\
\text { participation, promote polycentric governance systems }\end{array}$ \\
\hline \multicolumn{3}{|c|}{ Ostrom 1990, Anderies et al. 2004} \\
\hline & $\begin{array}{l}\text { Governance of resource systems and associated } \\
\text { infrastructure }\end{array}$ & $\begin{array}{l}\text { Principles for governing sustainable resources: clearly defined boundaries, } \\
\text { proportional equivalence between benefits and costs, collective-choice } \\
\text { arrangements, monitoring, graduated sanctions, conflict-resolution } \\
\text { mechanisms, rights to organize, nested enterprises }\end{array}$ \\
\hline \multicolumn{3}{|c|}{ Bohensky and Maru 2011} \\
\hline & $\begin{array}{l}\text { Natural resource management and indigenous knowledge } \\
\text { systems }\end{array}$ & $\begin{array}{l}\text { Four principles for integration: the need to develop new frameworks for } \\
\text { integration, greater cognizance of the social contexts of integration, expanded } \\
\text { modes of knowledge evaluation, involvement of intercultural "knowledge } \\
\text { bridgers" }\end{array}$ \\
\hline \multicolumn{3}{|r|}{ 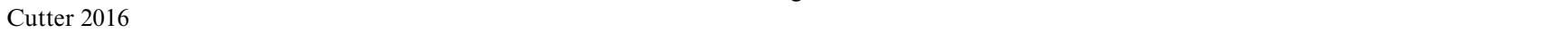 } \\
\hline & Community resilience & $\begin{array}{l}\text { Ten variables common to studies of community resilience: educational equality, } \\
\text { income, social capital, health access, mitigation plans, religious affiliations, } \\
\text { community aspirations, emergency management assets, mitigation activities, } \\
\text { infrastructure and buildings }\end{array}$ \\
\hline \multicolumn{3}{|c|}{ Wardekker et al. 2010} \\
\hline & Urban resilience (in context of climate change) & $\begin{array}{l}\text { In contexts of urban vulnerability, six principles identified: homeostasis } \\
\text { (feedback loops), omnivory (reduced vulnerability by diversification), high flux } \\
\text { (fast movement of resources), flatness (flattened hierarchy in social relations), } \\
\text { buffering (essential capacities come from multiple systems), redundancy } \\
\text { (overlapping functions) }\end{array}$ \\
\hline \multicolumn{3}{|r|}{ 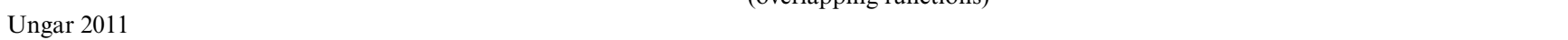 } \\
\hline & Psychosocial and cultural systems & $\begin{array}{l}\text { Four principles: decentrality (focus is on multiple systems), complexity } \\
\text { (solutions require complex interactions between systems), atypicality } \\
\text { (unconventional solutions may work best), cultural relativity (identifying which } \\
\text { systems work best is a value-based decision) }\end{array}$ \\
\hline \multicolumn{3}{|r|}{ 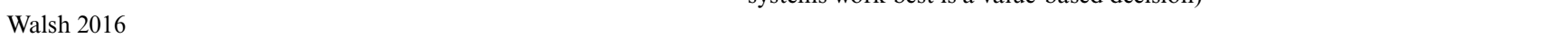 } \\
\hline & Family systems & $\begin{array}{l}\text { Nine key processes: making meaning of adversity, positive outlook, } \\
\text { transcendence and spirituality, flexibility, connectedness, mobilize social and } \\
\text { economic resources, clarity, open emotional sharing, collaborative problem } \\
\text { solving }\end{array}$ \\
\hline \multicolumn{3}{|r|}{ 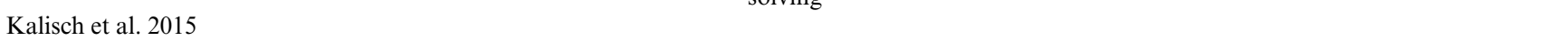 } \\
\hline & Neurological systems & $\begin{array}{l}\text { Positive appraisal style protects against stress through three classes of cognitive } \\
\text { processes: positive situation classification, reappraisal, interference inhibition }\end{array}$ \\
\hline
\end{tabular}


Masten 2011

Psychological systems

Prince-Embury 2013

Psychological systems

Ruhl 2011

Legal systems

Jackson and Ferris 2013

Engineered systems

Sterbenz et al. 2010

Computer network systems
Five-part resilience framework: mission (frame positive goals), models (include positive influences in designs), measures (assess assets and positive goals), methods (investigate preventative, promotional, and protective processes), multiple (engage with multiple systems)

Three core developmental systems that support resilience: sense of mastery, sense of relatedness, emotional reactivity

Properties of strategies used to design resilient legal systems: reliability, efficiency, scalabilty, modularity, evolvability

14 organizing principles: absorption,; physical redundancy, functional redundancy, layered defense, human in the loop, reduce complexity, reorganization, repairability, localized capacity, loose coupling, drift correction, neutral state, internode interaction, reduce hidden interactions

Four categories of principles: prerequisites (service requirements, normal behavior, threat, and challenge models, metrics, homogeneity), trade-offs (resource trade-offs, complexity, state management), enablers (self-protection, connectivity, redundancy, diversity, multilevel, contest awareness, translucency), behavior (self-organizing, adaptable, evolvable) conducting the research has been accounted for in the selection of themes. In the case of this synthesis, the disciplinary diversity of the many experts that were consulted should be taken into account when reviewing the list of common principles. A different team with different backgrounds might read the data differently much as innovative statistical tools have the power to add new layers of interpretation to quantitative data. Furthermore, not all principles drawn from the original papers could be fully accounted for by the final list of principles. In those cases where there were discipline-specific principles that disagreed with those of other disciplines, these differences are noted (Thomas et al. 2012).

\section{SEVEN PRINCIPLES}

Although far from exhaustive, Table One summarizes organizing principles from a purposefully selected, disciplinarily diverse number of syntheses of the resilience literature. Some of these papers are more comprehensive than others (e.g., $\mathrm{Xu}$ and Kajikawa's [2017] and Ostrom [2009]), drawing together findings from a broader range of disciplines.

By searching for commonalities and differences among these lists of principles, seven conceptual clusters were identified that reflect current thinking across disciplines. These include: (1) resilience occurs in contexts of adversity; (2) resilience is a systemic process (five distinct processes are identified); (3) there are trade-offs between systems when a system experiences resilience; (4) a resilient system is open, dynamic, and complex; (5) a resilient system promotes connectivity; (6) a resilient system demonstrates experimentation and learning; and (7) a resilient system includes diversity, redundancy, and participation. Although there are nuanced differences in how each principle and process is applied to human, built, and ecological systems (Quinlan et al. 2016), there is enough evidence to suggest that each principle should be considered when studying how systems sustain their functioning after exposure to an atypical stressor (e.g., social adversity or perturbation in the natural environment).

\section{Principle 1. Resilience occurs in contexts of adversity}

Resilience is not the same as patterns of growth that occur in a predictable or optimal environment. Although each discipline describes this principle slightly differently, in general the study of resilience refers to a return to balance (i.e., homeostasis) whether through recovery, adaptation, or transformation (see Principal 2 below) after there has been an atypical perturbation or stress exposure. In the field of psychology, for example, the phrase "positive development" refers to population-wide changes that are desirable, regardless of level of risk exposure (e.g., sense of belonging to one's community [Lerner 2014]), whereas resilience is distinguished by survival or thriving in contexts under stress (Ungar 2015a). The nature of these survival strategies can, however, vary from hyperarousal to hypoarousal depending on individual genetic predispositions. Both responses are typical of individuals experiencing chronic activation of the body's stress response (i.e., allostatic load) and the wear and tear that frequently results (Obradovic 2012, Ellis and Del Giudice 2014). Regardless of the pattern of coping an individual demonstrates, resilience is experienced if the strategies employed mitigate the cumulative impact of repeated exposure to stressors such as domestic or community violence (Lupien et al. 2001, Boxer et al. 2013) on human biological and social systems. The quality of the adaptive strategies used by these systems to achieve and sustain resilience are specific to the quality and quantity of the stress that the system experiences and the potential efficacy of each strategy in different contexts.

The same principle is observable at the level of natural environments. If the load of an external or internal stressor is too great or too persistent (e.g., an oil spill rather than the slow perturbation of seeping oil from a shipwreck), coping strategies available to handle the stress may fail and a system-wide breakdown, whether human or ecological, is likely to follow (Raglan and Schulkin 2014). A second example of this principle taken from environmental science is the regenerative capacity of a forest after a fire. If a forest retains soil (and the soil is improved by the fire) then a process of secondary succession may occur in 
which grasses and other herbaceous plants grow back. In this optimal case, a normal cycle of growth takes place because the ecosystem is healthy enough to regenerate. A very different cycle of adaptation (resilience) occurs following clearcutting if the soil is left to erode. In those cases, primary succession must first take place. Lichen, algae, and fungi are required to build up soil before the grasses and herbaceous plants establish themselves (Biggs et al. 2012). Without understanding the stressors that are present, it is pointless to suggest a population-wide solution (e.g., replanting trees). Each perturbation of the forest requires different regeneration strategies just as each type of systemic adversity requires its own unique pattern of adaptation.

In the area of human-dominated systems, there is the same need to account for risk exposures when deciding if a system shows resilience or not. For example, following Hurricane Katrina, adults who showed the lowest rates of mental distress tended to be those that had stable housing, lived in a salaried household, and had fewer (or no) children to care for (Abramson et al. 2008). Each of these protective factors played an important role in moderating the impact of an environmental disaster and making adults and family systems resilient in how they functioned.

\section{Principle 2. Resilience is a process}

Across disciplines, resilience is most often understood as a process rather than the static trait of a system (Masten 2014, Ungar 2015a, $b$, Martin et al. 2016). In human biology, psychology, and even economics, we misspeak when we say "a child (or the child's epigenome or the child's family or community) is resilient." If such a phrase is used, and used accurately, it should describe a human system as resilient if that system is engaged in a continuous process of acquiring and sustaining the resources required to function well under stress (Ungar 2011). The most noteworthy exception to this principle of resilience as process is writing in the field of social-ecological systems where resilience is most often described as the capacity of a stressed system (a trait of the system) to reach a new threshold and achieve balance, return to a previous state of balance, or transform into a new state of equilibrium (Gunderson and Holling 2002). Those studying social-ecological systems argue that resilience is the capacity of the system itself. There is less focus on the process whereby this temporary state is achieved than description of the state itself.

A less discipline-specific reading of the literature, including research by those studying social-ecological systems, suggests that this concept of resilience as process can be applied to both natural systems and when humans interact with those systems. To illustrate, although a degraded forest that recovers may be described as resilient (a trait) because it sustains new vegetation growth after clearcutting, it could also be argued that the forest is in a continuous process of recovery, adaptation, and transformation by which it responds to a threat such as unsustainable harvesting practices. Although this definitional debate is partially semantic (as all disciplines describe systems that are essentially functioning under conditions of atypical stress), the difference in how resilience is described (trait or process) has unnecessarily separated the fields of natural and material science from the human sciences. Despite the ontological disagreements, thinking about resilience as a process builds bridges between disciplines. Therefore, it can be asserted that systems of all kinds engage in processes that improve the capacity of their constituent elements (i.e., a child, a tree, a computer network) to cope with adversity which, in turn, leads to changes in the sustainability of one or more cooccurring systems. For example, in the realm of psychosocial systems like demobilized child soldiers in Sierra Leone who are being reintegrated into their communities, Betancourt (2012) showed through her longitudinal research that there are dynamic processes at play that protect the children and promote better adjustment. Although each system (the child and the community that must invite them back in) needs to have traits that will make reintegration work, it is the process of children and communities interacting that makes it possible for children to demobilize successfully and avoid the debilitating effects of trauma afterward. Although there are trade-offs (one system's resilience comes at the expense of another's-see Principle 3 below), resilience will typically characterize the process that the focal system is engaged in to reach a desired state, not the end state that is achieved. In the previous example, communities may experience the presence of the child soldiers as potentially traumatizing or physically threatening. Although they may be safer overall after demobilization and reintegration, resilience of the child-community system comes at the cost of disruption to the community's insular pattern of coping with the civil war by maintaining psychological and social boundaries.

Looking across all the disciplines represented in Table One, there is evidence of five processes that contribute to changes that make systems more sustainable in contexts of adversity: (a) persistence; (b) resistance; (c) recovery; (d) adaptation; and (e) transformation.

\section{a. Persistence}

Although a system's stability makes the system look like it is "resting" and in a state of balance, the system's resilience is its persistence to maintain stable functioning as internal and external stressors threaten to make it change (Hobfoll 2011). The system has the capacity to change, but that capacity is as yet unrealized. Its energy is directed to maintaining order. To illustrate, the concept of persistence as a process associated with resilience could be applied to a geographically remote traditional society that has maintained centuries-old social practices, or an anxious student's mediocre academic performance despite demands from her parents that she realize her full potential and achieve more. Even though internal and external factors insult both systems and make reorganization necessary (i.e., social relations within a traditional society are under pressure to adapt to a market economy; the student is encouraged to go to college), the persistence of the system depends on both its capacity to keep doing what it is doing and the capacity of cooccurring systems to protect it from disturbance. For example, government policies can facilitate (although rarely have) land claims settlements and respect for the human rights of indigenous peoples to create conditions where cultural practices can persist without threat. And in a situation where college is a right of all students and admission criteria are set low, an underperforming student will be able to persist with her behavior and still experience a reasonable amount of success. In both examples, at different systemic levels, the persistence of the focal system despite outside influence is not just the capacity of the system to remain unchanged, but the capacity of other contingent systems to resist change on behalf of the stable system. Simply stated, persistence is a process of continuity where there is a potential for change but change has not been necessary 
because the load on the system (its experience of adversity) has yet to overwhelm the resources available to the system that are keeping the system stable.

There is evidence, however, that persistence may describe how one part (or scale) of a system experiences resilience even as other parts of the same system change. For example, urban designers Salat and Bourdic (2012) have noted that, in general, streetscapes show far more persistence (they describe this as permanence) than the houses themselves. Likewise, the rooms inside those homes are more likely to be remodeled in a shorter period of time than their façades. Each nested level of the community's architecture can persist at a different pace. Change at one level (a kitchen remodel) does not necessarily change the persistence of the entire system (the community's identity continues to be reflected in the style of its homes, much as the canal houses in Amsterdam give the city its architectural identity despite having been extensively renovated inside).

\section{b. Resistance}

Although persistence describes a system that keeps doing what it has been doing because it has the supports it needs to avoid threat, resistance describes a process whereby a system is at risk of being overwhelmed by internal or external stressors and must actively use its resources to resist creating new regimes of behavior. Resistance makes it possible for the system to continue functioning even when a perturbation is present. For example, communities like the 9th Ward in New Orleans and other neighborhoods vulnerable to flooding that resettle in the same place after a natural disaster might be said to show resilience, but the process keeping that community functioning is its ability to resist government pressure to relocate (Gotham and Campanella 2013). Depending on one's value proposition, the community's resistance to change may or may not be a sign of its resilience. Resistance may result in the sustainability of a normative state or patterns of resilience that threaten the long-term viability of the system as a whole.

Likewise, and somewhat paradoxically, the act of resistance to change may cause one part of a system to enter into a new regime that allows the larger system to resist change more effectively. For example, forced displacement after a natural disaster might result in a population's heightened awareness of their experience of social marginalization and political activism, even if their right to return to their land imperils them in the future. Indeed, a political, biological, or environmental system can be very resilient and able to withstand pressure to change (i.e., the system shows robustness [Anderies et al. 2016]), even though the regime it maintains is undesirable (e.g., a political system keeps its dictator in power; a patient avoids physical activity even after surgery makes greater movement possible; a degraded ecosystem keeps invasive species out even if these could improve the system's diversity and viability).

\section{c. Recovery}

The process of recovery (also commonly described as a system's capacity to "bounce back" [Zolli 2012]) is conceptually problematic as it implies a return to the same level of "normal" functioning that was present before the system was disturbed. The return to a previous state, however, is improbable if new information has been introduced to help the system cope with the disturbance. Recovery is instead a complex process of rebuilding, repair, and adaptation that characterizes an individual and collective movement toward a new behavioral regime even if that new regime looks similar to a previous one. For example, in response to the devastating earthquake Christchurch, New Zealand experienced in 2011, new building codes were enacted for earthquake-prone buildings to help them withstand similar potentially catastrophic events in the future. Likewise, a recovered ecosystem (e.g., a reclaimed wetland) is always influenced by its management even if it looks superficially similar to the state it was in before it was degraded and repaired. Even computer systems (e.g., the Internet) can demonstrate recovery after disturbances like power outages and cyberattacks (Sterbenz et al. 2010). These processes of recovery, synonymous with resilience, are also likely to see an improvement in the function of the computer network in part or as a whole as a consequence of the recovery effort. In each of these examples, the system's purpose is to return to a previous pattern of functioning. Change, when it does occur, is an unintended consequence.

\section{d. Adaptation}

Whereas recovery returns a system to a previous state, adaptation describes the process of a system adjusting and learning new ways of functioning after an insult. The system changes its functioning in order to be sustainable, facilitated by concurrent changes to other systems that are necessary to accommodate the new focal system's new behavioral regime. For example, the resilience of health systems has been described by Kruk and her colleagues (2015) "as the capacity of health actors, institutions, and populations to prepare for and effectively respond to crises; maintain core functions when a crisis hits; and, informed by lessons learned during the crisis, reorganise if conditions require it" (Kruk et al. 2015:1910). The advantage of resilience is the longterm capacity (the resilience dividend) to accommodate stress, much as childhood immunization produces a lifetime of protection against disease through exposure to a manageable stressor that triggers a change in the immune system. This adaptation, however, should not be understood as the capacity of any one system alone. Adaptation is a messy set of interactions occurring simultaneously across multiple systems at multiple scales.

\section{e. Transformation}

In some instances, a system radically transforms itself into something new (e.g., posttraumatic growth in humans [Vaillant 2015]; a technological breakthrough such as the ride-sharing service Uber). In other instances, the system imposes or is the subject of a transformation of the environment that surrounds it that makes the focal system more sustainable (e.g., a policy change that results in a threatened wetland being transformed into a protected national park) (Folke et al. 2010, Cox 2014, Brown 2016). Transformation, however, like adaptation, describes change but does not predict the desirability of the change. Just as ecological systems are transformed as they cope with increasing levels of pollution by depopulating and losing biodiversity, and human systems may become temporarily more violent to cope with a potentially catastrophic event (such as the rise of fascism), transformation as a resilience process is associated with constructions of meaning that determine if a change is experienced as advantageous to one or more parts of a system. A coral reef, for example, may be transformed into an environment with less ecological diversity by an invasive species 
or a rise in the level of phosphorous in the water (Quinlan et al. 2016). The reef's new regime will appear (from an anthropocentric perspective) weakened to outsiders even though from the point of view of the few species that exploit the less competitive ecosystem their new environment is optimal. In this sense, the reef is transformed into a different regime with fundamentally different qualities. Typically, the term resilience is used in most disciplines with a bias toward transforming systems into becoming more, not less, desirable and complex.

The benefits of resilience to a system, however, are not equitably distributed across the system. Resilience systems, therefore, show both equifinality (many means to a single end), which is characteristic of their capacity to adapt, and multifinality (many desirable ends from many different means), which contributes to unpredictable forms of transformation. For example, a community dependent upon resource extraction may change mining practices or find new mineral reserves to keep their town economically viable when commodity prices for one type of ore drops (the town is still a mining town - an example of equifinality - even though it has transformed how and what it extracts). Likewise, the town may choose to diversify its economy, continuing to mine but encouraging tourism or using spent mines as scientific laboratories (this has occurred in communities like Sudbury, Canada - an example of multifinality). Each of these modes of transformation increases the capacity of one or more systems to experience resilience.

\section{Principle 3. There are trade-offs between systems when a system experiences resilience}

Although systems show a tendency toward maintaining balance, resilience (as a process) does not mean that all parts of a system, or cooccurring systems, benefit equally when a system appears stable. Trade-offs are always evident. Which part of a system is found to show resilience depends on the vantage point of the observer and the metrics used to assess whether a system is perceived as improved or degraded by a disturbance. In fact, perturbation may produce more desirable outcomes by "steeling" a system to stress and making it better able to cope in the future. As Salat and Bourdic (2012) explain, "The fundamental notion that defines the stability of physical systems is that states are only stable if minor perturbations reinforce rather than destroy them" (p. 61). It follows that for every experience of resilience a system engages in (including a phase of vulnerability before growth), there will be trade-offs. Some parts of the system will degrade, whereas others are strengthened. In the sphere of medical anthropology, for example, Panter-Brick and Eggerman (2012) have described how the rigid structure of Afghani families both protects against external threats while also causing frustration, which leads to mental disorder when excessively high expectations for how one must behave cannot be reasonably met. Likewise, when we as humans seek to make an ecosystem more resilient (according to us), we are likely to encounter systemic forces that prefer a different outcome. There will always be winners and losers with regard to which systems manage to experience resilience and which do not. Although the resilience of any one system may well benefit the resilience of other systems, it is possible that the process of coproduction of power and the dynamic competition for resources in environments with fixed boundaries (and therefore limited potential for access to new resources) will mean that one system's resilience can adversely impact the resilience of another system, whether that system is human or a part of the environment.

To illustrate this principle, an ecosystem like farmland that is relied upon to produce food may become more diverse after a farm foreclosure that leaves land fallow if native plant species are allowed to invade the fields. The principle of trade-offs (and the winners and losers that result) can inform a broader understanding of how ecosystems under stress are changed and our anthropocentric bias toward a specific outcome such as maximum sustainable yield (Gunderson et al. 2010). Therefore, nurturing the resilience of systems (whether an individual, community, or ecosphere) requires attention to both the opportunity structures that facilitate a system's change, as well as the different amounts of power each system and its components can exercise to influence which regime is preferred (Folke et al. 2016, Nyborg et al. 2016). In practical terms, this means addressing a complex problem such as climate change will depend on who controls the social discourse, whether communities can adapt to changing climates, and whether the environment can remain sustainable in ways that serve the needs of humans. There are multiple trade-offs to be taken into account as we determine which system, or systems, are showing resilience and who or what benefits the most. It is not surprising, however, that resilience researchers have been fundamentally anthropocentric in their orientation. Reciprocity between human and environmental systems is occasionally mentioned, but most of the research to date has been concerned with what these interactions mean for human wellbeing. It is just as valid, of course, to consider the impact of the destruction of habitat on animal and plant systems without reference to the utility of these systems to humans (Naess 1989). Doing so changes our perspective of who benefits and whose survival is threatened when one part of a system experiences resilience at the expense of another.

\section{Principle 4. A resilient system is open, dynamic, and complex}

A system's resilience typically requires that a system be open to new information, although here too there are exceptions when openness brings with it vulnerability to external threats. Despite this caveat, in fields other than social-ecological systems, an ontological error is made when terms like equilibrium and balance are used as synonyms for resilience. As a process, resilience is a measure of how well a system integrates environmental shocks and initiates new behavioral regimes. Whereas stressors may originate from within the system, or from a cooccurring system, the resources to accommodate a stressor are typically the result of complex, reciprocal relationships between systems that involve many different factors at once (Prilleltensky and Prilleltensky 2007, Southwick et al. 2014b). In the field of architecture, for example, this open, dynamic, and complex understanding of resilience is causing architects to rethink the variables considered when developing strategies that encourage homeowners to renovate their homes to be more energy and water efficient. van Hal (2014) argues that designers must account not only for the materials and funding available for the renovations (two different supraordinate systems), but also the irrational emotionality that causes homeowners to resist or embrace change. This same complexity is evident in efforts to facilitate the resilience of persons displaced in the context of climate change during their period of resettlement. Their often tenuous situation requires a long list of concurrent interventions such as language instruction 
and other educational and retraining supports, housing in geographically secure settings, social integration strategies to increase tolerance, family reunification policies, psychological counseling (if needed), and economic opportunities (Ott and Mongomery 2015). No single system predicts positive resettlement but, when combined, access to services, supports, and a benign environment can produce economic and social outcomes for refugees that exceed those of the general population of a host country (Hou and Bonikowska 2016). This example, like the previous one regarding housing quality, must account for the tradeoffs that systems make and competing value judgments that privilege one set of outcomes over another.

To return to the example of climate change and refugees, one could argue that stable homogeneous social systems are destabilized and made less resilient by immigration. In this case, the openness of social and political systems may be perceived as threatening to a community's sustainability. This alternative interpretation is, of course, limited by its ideological and ahistorical point of view. Stable societies were themselves once disruptive of indigenous peoples and of the ecosystems they occupied. Although we can argue that not all resilient systems are open and complex at a single point in time, this argument is difficult to sustain if we introduce into our analysis temporal dimensions of resilience.

To further understand the complexity of resilience-promoting processes, whether of human or natural systems, there are a number of ways to describe changes that contribute to a system's resilience. Ecologists, for example, use concepts like slow and fast variables to characterize feedback leading to growth or degradation of natural environments (Walker and Salt 2012). Fast variables are a cataclysmic event (an episode) that produces significant change in a system's regime, whereas slow variables accumulate over time. The slow sedimentation of a river bed due to agricultural runoff or human migration from rural to urban areas are both slow variables that create a cascade of outcomes through feedback loops. Thinking in terms of the speed of variables and feedback makes it clear that no single factor makes a system resilient. The nature of each system (at any level) and the complexity of the resources it has available will make it more or less capable of anticipating and responding to change.

\section{Principle 5. A resilient system promotes connectivity}

Whereas openness is a description of a system's capacity to tolerate heterogeneity, connectivity refers to how well components of systems interact with one another during a crisis. It has been suggested that the more collaborative the network (e.g., the more organizations are coupled together without becoming too enmeshed or too disengaged), the more likely systems are to solve complex problems (Bodin 2017). This connectivity, however, is only effective if the nature of the relationships fits the task to be accomplished and can adapt to the constraints of the social and physical ecologies that influence the behavior of different actors. As Bodin (2017) shows with regard to a fishery, governance structures can promote a sustainable industry if fishers that catch different species collaborate to ensure that no single fish species is overharvested. If that was to occur, the viability of other fish stocks would decline as the trophic interactions between species would be compromised and the overall viability of the fishery diminished. In this example, not only is there connectivity between the fishers, but also between the fishers and their catch and between the various parts of the underwater ecosystem that depend on each other for survival. In contexts where there is a common pool resource, the principle of connectivity will need to be specific to the context if it is to support the resilience of one or more systems (Anderies et al. 2016).

Once again, epistemological differences within the resilience literature raise issues related to how much and what kind of connectivity is helpful, and the trade-offs that accompany systems when they work together. In simple ecological terms, a disturbance like a storm may destroy habitat that is regenerated through the movement of plants and animals from an adjacent ecosystem. Human connectivity is similarly helpful to resilience, with relationships being theorized as critical to buffering the impact of a stressor like rural poverty in poorly functioning environments (Theron 2015) or preventing a pregnant mother's exposure to intimate partner violence (Bush et al. 2017). Connectivity can, however, also threaten resilience if proximity contributes to the migration of invasive species, toxic substances, or, in human terms, exploitation of one group by another. These negative consequences of connectivity do not necessarily diminish the value of the concept to understanding resilience. The value of connectivity, like other resilience principles, must be assessed with regard to whether connections facilitate positive or negative growth. These are value-laden judgments that depend on who is defining resilience and the desirability of the outcomes being sought. It can be difficult to discern when connectivity is bad or good. For example, although exposure to infectious diseases or potentially dangerous bacteria is generally discouraged, in the right doses during a child's development, a child's immune system and microbiome are both enhanced by immunization and an optimal environment rich in bacteria, both requirements for healthy development (Greenhalgh et al. 2016). Likewise, an urban forest that is cut off from natural fires or invasive species may not be sustainable over time. Whereas connectivity brings with it potential for increased vulnerability, the potential benefits of connectivity may not be evident immediately if in the short-term a system appears degraded following a perturbation.

\section{Principle 6. A resilient system demonstrates experimentation and learning}

Systems experience more resilience the more they include opportunities to experiment with new solutions, reflect on the impact of experience, and integrate learning into future efforts to adapt (Cutter et al. 2008a, b, Rocha et al. 2015, Carson and Peterson 2016). Connectivity (Principle 5) shapes opportunities to learn by limiting or enhancing exposure to novel experiences. In psychology, a similar concept to experimentation appears in theories of human development. Vygotsky (1978) showed that successful development is the result of supportive environments that provide "scaffolding" to facilitate new experiences and associated learning. The child progresses when pushed toward a "zone of proximal development" where manageable amounts of stress are experienced and learning occurs. Ecological systems also learn through experimentation, with contingent systems providing feedback with regard to the viability of changes that are made. As environments constantly change (e.g., the temperature of an ocean rises, or there is an infestation of a pest on an isolated island), the resilience of any one species or system will be a reflection of its capacity to innovate new regimes (e.g., fish stocks in the ocean migrate to cooler waters, leaving space for 
new species to exploit food sources, which themselves adapt to warmer water; an island subspecies flourishes because its predators decrease in number or are exterminated altogether). Humans in interaction with natural environments may also facilitate the development of new ecological and social regimes (e.g., wildlife management changes human-nature relationships; melting northern ice due to human activity is changing migration patterns among large mammals). In all of these examples, systems must learn to adapt and experiment with new ways of coping. Ideally, feedback loops ensure that lessons learned make systems more robust and better able to adapt to future challenges (Pahl-Wostl 2009).

\section{Principle 7. A resilient system includes diversity, redundancy, and participation}

A system's diversity means it has sufficient resources to function when stressed or compromised (Hobfoll 2011). The more components that are ready to take over when one part of the system fails the more sustainable the system is as a whole, much as layers of failsafe systems on airplanes are designed for redundancy. The three concepts work together. When a system is insulted, it is unlikely that the challenge will present the same risk to all parts of the system at once. The more diverse the system is (the more ways it has to solve problems), the less vulnerable it will be to perturbations (Biggs et al. 2015) and the more resilience it will show. For example, a 3-year study of a multiethnic cohort of six-year-olds and their academic achievement showed that classroom environment, peers, and teachers had different effects on reading and math scores, with social relationships influencing reading but not math performance (Liew et al. 2018). In this example, a system like a child can be influenced by multiple systems (classroom environment, peers, and teachers). The more of these systems that cooccur in the same space at the same time, the more likely the child is to succeed in at least one domain, especially when learning and living conditions are suboptimal. Furthermore, there is evidence that increasing the number of systems at play (e.g., improving the child's home environment, too) might further improve the child's academic performance (Nix et al. 2005).

Redundancy, however, is not simply about duplication of resources or broadening the pool of participants engaged in solving a problem. The resilience of systems also depends on where that redundancy is located and its capacity to handle the load after a crisis occurs. Sterbenz et al. (2010) give several examples of the nuances of redundancy, such as a fire at a major telecommunications center in Hinsdale, Illinois in 1988 that destroyed both the primary and backup power systems housed in the same building. Likewise, a train accident in the Howard Street Tunnel in Baltimore in 2001 seriously impeded Internet traffic as multiple providers used the tunnel as a convenient way to route cable. Although in both examples, alternatives were available (i.e., each system had built-in redundancies), their capacity was insufficient to cope with the load that each experienced (the communications center fire was too large; the tunnel accident unusually destructive). Redundancy makes systems more resilient but redundancy, like other elements of resilience, also needs to be sufficiently complex and connected to ensure that resilience remains possible

Thus, systems are, in general, stronger when more elements across more systems participate. Drawing on an example at a very different systemic level, community participation in decisionmaking improves the likelihood that new strategies will be found that lead to better regimes for human-environment interaction (Cutter et al. 2014). Participation is more likely to occur, however, if the solutions that are being sought have meaning (are important to survival) for those parts of a system that are being asked to engage (Usdin 2014, Wessells 2015). For example, human management of a natural ecosystem may prevent destruction of the ecosystem from an ecological risk (e.g., an invasive species) or human-made risk (e.g., poaching) if governance structures support community engagement in finding and implementing solutions. In this case, it is the diversity of stakeholders involved, the redundancy of their roles, and their active participation in processes to improve the resilience of social-ecological systems that makes both natural and social environments more sustainable.

\section{CONCLUSION}

If there is any consensus in the field of resilience it is that the potential of the construct has yet to be fully realized (Ungar 2011, Southwick et al. 2014a, Fischer et al. 2015). Previous efforts to discern a set of guiding principles have arrived at the same conclusion. Most notably, Biggs et al. (2015) aggregated the research on the design of ecosystem services to enhance the capacity of systems to withstand perturbations and found support for a different but related set of seven principles. Reviewing those principles, Schlüter et. al. (2015) argue that none were yet fully understood and many show a remarkable amount of fluctuation in how they look in practice, depending on the context in which they are applied. For example, more diversity is only desirable in some contexts (e.g., too much diversity can make it difficult for a community to reach consensus). Likewise, connectivity, although valuable when enhancing resilience, also makes it easier for a disturbance to imperil the functioning of every part of a system if the parts of that system are too enmeshed. Similarly, participation in governance is beneficial to a system's stability and transformation, but only if issues related to differences in power between participants are addressed. None of this, however, refutes the need for organizing principles to understand resilience, especially when looking beyond specific bodies of resilience research in the social and natural sciences. The complexity suggested by the lists of possible principles found in the literature does, however, make it necessary to proceed with caution. Building on existing evidence, it can be argued that resilience is a systemic and multiscale reciprocal process with a common set of principles. The seven principles (and five processes) described in this paper provide a comprehensive, albeit still developing, explanation for human-nature, human-materials, or in psychological science, person $\mathrm{x}$ environment interactions.

Although human systems are unique in their capacity to exercise agency, there is remarkable synergy in how resilience is realized by human, material, built, and natural systems. The diversity of constructs that have been associated with resilience across disciplines, however, suggests the need for an inductive rather than deductive approach to synthesis if resilience is to become a grand theory. By purposefully selecting syntheses of the resilience research until repetition of principles reached saturation, it was possible to identify clusters of common principles that reflect much of what is already known about the construct. Previous syntheses have described this variety but have not provided a practical summary of these principles or a critical reading of the 
literature across systems and disciplines to reconcile common principles with negative case examples. Indeed, reliance on quantitative syntheses of the literature has not answered the core question of whether the resilience of different systems at different scales can be accounted for by a common set of principles, and what these principles are.

The set of seven principles discussed in this paper may also help to further research on resilience by providing a map of common themes that should be explored. For example, it is becoming increasingly common to study resilience at multiple systemic levels even though, in the absence of a common set of organizing principles, the specific aspects of resilience that are studied tend to be idiosyncratic to each independent piece of research. One can see this in even high quality work such as that by Jackley et al. (2016), who investigated the way indigenous communities on Canada's west coast maximized seafood production through the maintenance of clam gardens. That study showed that communities increased the resilience of their food supply through modifications of their environment. Clams grown in the gardens gained as much as twice the biomass of noncultivated clams, making them a better food source for the harvesters and increasing the sustainability of these coastal communities. In this example, the health of the ecosystem, and the capacity of the human system to work collectively, are both parts of a well-functioning socialecological system of seafood production that reflects all seven resilience principles described in detail earlier. Psychologists, human geographers, computer engineers, lawyers, and ecologists (along with many others) are charting similar conceptual territory to explore the biopsychosocial, economic, political, and environmental interactions that make systems not only sustainable but more likely to grow in desirable ways after a disturbance. If these different bodies of research are going to inform one another, they will need a common set of principles with which to interpret findings.

Identifying shared principles (and processes) of resilience across systems may also facilitate the building of bridges between disciplines and inform the design of interventions that facilitate the recovery, adaptation, or transformation of systems under stress. In brief, there is evidence to support the assertion that adherence to the principles outlined in this paper will make it easier to facilitate resilience across cooccurring systems. For example, a community's vulnerability that results from circumstances (present day and historic) related to the mental health of its members, income distribution, education levels, housing, threats to racial and ethnic cohesion, or the integrity of the surrounding built and natural environments, will require interventions that improve the capacity of multiple systems to cope with adversity at the same time (Pfefferbaum et al. 2006, Kofinas et al. 2013). Where such communities have been the focus of study, interventions have put into practice most, if not all, of the seven principles (e.g., interventions promote connectivity, encourage participation, acknowledge trade-offs, etc.). It is reasonable to conclude that there are intervention designs that are more likely to stimulate changes that systems experience as positive when these principles are applied (Adger 2006, Fordham et al. 2013, de Jong et al. 2015, Ungar 2016). This is especially the case when problems of sustainability (such as those related to climate change) create complex demands on systems to adapt (Cox 2007, Archibald and Munn-Venn 2008, Popa et al. 2015).
As this review was purposeful rather than exhaustive, the list of seven principles is not definitive. They do, however, contribute to the ontological and epistemological debates that have plagued resilience research, while also offering a challenge to the incommensurability hypothesis. Where discordant points of view exist, these have been noted. As discussed under methods, a different set of scholars might identify a different list of shared principles, although their list would likely be similar to that described here given the level of qualitative engagement with the literature and the conversations with experts that were used to craft this paper. This work, then, is another step (but certainly not the last step) in the conceptual development of an emerging and exciting field of inquiry that is helping to change the way we approach the most challenging problems facing humans and built and natural environments.

Responses to this article can be read online at: http://www.ecologyandsociety.org/issues/responses. php/10385

\begin{abstract}
Acknowledgments:
The author wishes to extend special thanks to the many researchers who helped review earlier drafts of this paper and who contributed their insightful comments, in particular, Linda Theron (University of Pretoria), Robin Cox (Royal Roads University), and Joanne Weinberg (University of British Columbia). Thank you as well to the Canadian Institutes for Health Research (Grant \#IP2-150708), the Social Sciences and Humanities Research Council of Canada (Grant \#885-2008-1000), and the Canadian Institute for Advanced Research for their support of the research that has been the basis for this paper.
\end{abstract}

\section{LITERATURE CITED}

Abramson, D. M., Y. S. Park, T. Stehling-Ariza, and I. Redlener. 2010. Children as bellwethers of recovery: dysfunctional systems and the effects of parents, households, and neighborhoods on serious emotional disturbance in children after Hurricane Katrina. Disaster Medicine and Public Health Preparedness 4 (Suppl 1):17-27. https://doi.org/10.1001/dmp.2010.7 http://dx. doi.org/10.1001/dmp.2010.7

Abramson, D., T. Stehling-Ariza, R. Garfield, and I. Redlener. 2008. Prevalence and predictors of mental health distress postkatrina: findings from the Gulf Coast child and family health study. Disaster Medicine and Public Health Preparedness 2(2):7786. http://dx.doi.org/10.1097/DMP.0b013e318173a8e7

Adger, W. N. 2006. Vulnerability. Global Environmental Change 16(3):268-281. https://doi.org/10.1016/j.gloenvcha.2006.02.006 http:// dx.doi.org/10.1016/j.gloenvcha.2006.02.006

Anderies, J. M., M. A. Janssen, and E. Ostrom. 2004. A framework to analyze the robustness of social-ecological systems from an institutional perspective. Ecology and Society 9(1): 18. [online] URL: http://www.ecologyandsociety.org/vol9/iss1/art18/ http:// dx.doi.org/10.5751/ES-00610-090118

Anderies, J. M., M. A. Janssen, and E. Schlager. 2016. Institutions and the performance of coupled infrastructure systems. 
International Journal of the Commons 10(2):495-516. https://doi. org/10.18352/ijc.651 http://dx.doi.org/10.18352/ijc.651

Archibald, A., and T. Munn-Venn. 2008. Building resilience: leadership and accountability. Conference Board of Canada, Ottawa, Ontario, Canada.

Baggio, J. A., K. Brown, and D. Hellebrandt. 2015. Boundary object or bridging concept? A citation network analysis of resilience. Ecology and Society 20(2): 2. https://doi.org/10.5751/ ES-07484-200202 http://dx.doi.org/10.5751/ES-07484-200202

Baggio, J. A., S. B. BurnSilver, A. Arenas, J. S. Magdanz, G. P. Kofinas, and M. De Domenico. 2016. Multiplex social ecological network analysis reveals how social changes affect community robustness more than resource depletion. Proceedings of the National Academy of Science 113(48):13708-13713. https://doi. org/10.1073/pnas.1604401113 http://dx.doi.org/10.1073/pnas. 1604401113

Barnett-Page, E., and J. Thomas. 2009. Methods for the synthesis of qualitative research: a critical review. BMC Medical Research Methodology 9(1):59. https://doi.org/10.1186/1471-2288-9-59 http:// dx.doi.org/10.1186/1471-2288-9-59

Berkes, F., J. Colding, and C. Folke. 2003. Navigating socialecological systems: building resilience for complexity and change. Cambridge University Press, Cambridge, UK. http://dx.doi. org/10.1017/CBO9780511541957

Berkes, F., and C. Folke. 1998. Linking social and ecological systems: management practices and social mechanisms for building resilience. Cambridge University Press, Cambridge, UK.

Betancourt, T. S. 2012. The social ecology of resilience in waraffected youth: a longitudinal study from Sierra Leone. Pages 347356 in M. Ungar, editor. The social ecology of resilience: a handbook of theory and practice. Springer, New York, New York, USA. http://dx.doi.org/10.1007/978-1-4614-0586-3 27

Biggs, R., M. Schlüter, D. Biggs, E. L. Bohensky, S. BurnSilver, G. Cundill, V. Dakos, T. M. Daw, L. S. Evans, K. Kotschy, A. M. Leitch, C. Meek, A. Quinlan, C. Raudsepp-Hearne, M. D. Robards, M. L. Schoon, L. Schultz, and P. C. West. 2012. Toward principles for enhancing the resilience of ecosystem services. Annual Review of Environment and Resources 37:421-448. https:// doi.org/10.1146/annurev-environ-051211-123836 http://dx.doi. org/10.1146/annurev-environ-051211-123836

Biggs, R., M. Schlüter, and M. L. Schoon. 2015. Pages 1-31 in R. Biggs, M. Schlüter, and M. L. Schoon, editors. Principles for building resilience: sustaining ecosystem services in socialecological systems. Cambridge University Press, Cambridge, UK. http://dx.doi.org/https://doi.org/10.1017/CBO9781316014240

Bodin, Ö. 2017. Collaborative environmental governance: achieving collective action in social-ecological systems. Science 357(6352): eaan1114. http://dx.doi.org/10.1126/science.aan1114

Bohensky, E. L., and Y. Maru. 2011. Indigenous knowledge, science, and resilience: what have we learned from a decade of international Literature on "integration?" Ecology and Society 16 (4): 6. http://dx.doi.org/10.5751/ES-04342-160406

Bousquet, F., A. Botta, L. Alinovi, O. Barreteau, D. Bossio, K. Brown, P. Caron, P. Cury, M. D'Errico, F. DeClerck, H. Dessard, E. Enfors Kautsky, C. Fabricius, C. Folke, L. Fortmann, B.
Hubert, D. Magda, R. Mathevet, R. B. Norgaard, A. Quinlan, and C. Staver. 2016. Resilience and development: mobilizing for transformation. Ecology and Society 21(3): 40. https://doi. org/10.5751/ES-08754-210340 http://dx.doi.org/10.5751/ES-08754-210340

Bousquet, F., P. Robbins, C. Peloquin, and O. Bonato. 2015. The PISA grammar decodes diverse human-environment approaches. Global Environmental Change 34:159-171. https://doi.org/10.1016/ j.gloenvcha.2015.06.013 http://dx.doi.org/10.1016/j.

gloenvcha.2015.06.013

Boxer, P., L. R. Huesmann, E. F. Dubow, S. F. Landau, S. D. Gvirsman, K. Shikaki, and J. Ginges. 2013. Exposure to violence across the social ecosystem and the development of aggression: a test of ecological theory in the Israeli-Palestinian conflict. Child Development 84(1):163-177. https://doi.org/10.1111/

j.1467-8624.2012.01848.x http://dx.doi.org/10.1111/ j.1467-8624.2012.01848.x

Brown, K. 2016. Resilience, development and global change. Routledge, New York, New York, USA. http://dx.doi. org/10.4324/9780203498095

Bush, N. R., K. Jones-Mason, M. Coccia, Z. Caron, A. Alkon, M. Thomas, K. Coleman-Phox, P. D. Wadhwa, B. A. Laraia, N. E. Adler, and E. Epel. 2017. Effects of pre-and postnatal maternal stress on infant temperament and autonomic nervous system reactivity and regulation in a diverse, low-income population. Development and Psychopathology 29(5):1553-1572. http://dx. doi.org/10.1017/S0954579417001237

Cadimaa, J., M. Enricob, T. Ferreiraa, K. Verschuerenc, T. Leala, and P. M. Matosavanro. 2016. Self-regulation in early childhood: the interplay between family risk, temperament and teacher-child interactions. European Journal of Developmental Psychology 13 (3):341-360. http://dx.doi.org/10.1080/17405629.2016.1161506

Carpenter, S., W. Brock, and P. Hanson. 1999. Ecological and social dynamics in simple models of ecosystem management. Ecology and Society 3(4): 4. [online] URL: https://www. ecologyandsociety.org/vol3/iss2/art4/ http://dx.doi.org/10.5751/ ES-00122-030204

Carpenter, S., B. Walker, J. M. Anderies, and M. Abel. 2001. From metaphor to measurement: resilience of what to what? Ecosystems 4(8):765-781. https://doi.org/10.1007/s10021-001-0045-9

Carson, M., and G. Peterson. 2016. Arctic resilience report. Arctic Council, Tromsø, Norway. [online] URL: https://oaarchive.arcticcouncil.org/bitstream/handle/11374/1838/ARR_full_report_lowres $161114 \mathrm{~b} . p d f$ ?sequence $=1$ \&is Allowed $=\mathrm{y}$

Cox, R. S. 2007. Capacity building approaches to emergency management in rural communities: recommendations from survivors of the British Columbia wildfires, 2003. International Journal of Emergency Management 4(2):250-268. https://doi. org/10.1504/IJEM.2007.013993

Cox, R. S. 2014. Disaster preparedness in Canada's North: what's resilience got do with it? Northern Public Affairs 2(3):43-45.

Cox, R. S., and M. Hamlen. 2015. Community disaster resilience and the rural resilience index. American Behavioral Scientist 59 (2):220-237. https://doi.org/10.1177/0002764214550297 http:// dx.doi.org/10.1177/0002764214550297 
Cutter, S. L. 2014. What makes events extreme? Journal of Extreme Events 1(1): 1402001. https://doi.org/10.1142/ $\underline{\mathrm{S} 2345737614020011}$

Cutter, S. L. 2016. Resilience to what? Resilience for whom? The Geographical Journal 182(2):110-113. https://doi.org/10.1111/ geoj.12174

Cutter, S. L., K. D. Ash, and C. T. Emrich. 2014. The geographies of community disaster resilience. Global Environmental Change 29:65-77. https://doi.org/10.1016/j.gloenvcha.2014.08.005 http:// dx.doi.org/10.1016/j.gloenvcha.2014.08.005

Cutter, S. L., L. Barnes, M. Berry, C. Burton, E. Evans, E. Tate, and J. Webb. 2008a. A place-based model for understanding community resilience to natural disasters. Global Environmental Change 18(4):598-606. https://doi.org/10.1016/j.gloenvcha.2008.07.013

Cutter, S. L., L. Barnes, M. Berry, C. Burton, E. Evans, E. Tate, and J. Webb. 2008b. Community and regional resilience: perspectives from hazards, disasters, and emergency management. Community and Regional Resilience Initiative, Oak Ridge National Laboratory, Oak Ridge, Tennessee, USA.

de Jong, J. T., L. H. Berckmoes, B. A. Kohrt, S. J. Song, W. A. Tol, and R. Reis. 2015. A public health approach to address the mental health burden of youth in situations of political violence and humanitarian emergencies. Current Psychiatry Reports 17 (7):1-10. https://doi.org/10.1007/s11920-015-0590-0. http://dx. doi.org/10.1007/s11920-015-0590-0

Dixon-Woods, M., D. Cavers, S. Agarwal, E. Annandale, A. Arthur, J. Harvey, A. J. Sutton. 2006. Conducting a critical interpretative synthesis of the literature on access to healthcare by vulnerable groups. BMC Medical Research Methodology 6: 35. https://doi.org/10.1186/1471-2288-6-35

Ellis, B. J., and M. Del Giudice. 2014. Beyond allostatic load: rethinking the role of stress in regulating human development. Development and Psychopathology 26(1):1-20. https://doi. org/10.1017/S0954579413000849 http://dx.doi.org/10.1017/ $\underline{\mathrm{S} 0954579413000849}$

Fischer, J., T. A. Gardner, E. M. Bennett, P. Balvanera, R. Biggs, S. Carpenter, T. Daw, C. Folke, R. Hill, T. P. Hughes, T. Luthe, M. Maass, M. Meacham, A. V. Norström, G. Peterson, C. Queiroz, R. Seppelt, M. Spierenburg, and J. Tenhunen. 2015. Advancing sustainability through mainstreaming a socialecological systems perspective. Current Opinion in Environmental Sustainability 14:144-149. https://doi.org/10.1016/j. cosust.2015.06.002 http://dx.doi.org/10.1016/i.cosust.2015.06.002

Folke, C. 2006. Resilience: the emergence of a perspective for social-ecological systems analyses. Global Environmental Change 16(3):253-267. https://doi.org/10.1016/j.gloenvcha.2006.04.002 http:// dx.doi.org/10.1016/j.gloenvcha.2006.04.002

Folke, C., R. Biggs, A. V. Norström, B. Reyers, and J. Rockström. 2016. Social-ecological resilience and biosphere-based sustainability science. Ecology and Society 21(3): 41. http://dx.doi.org/10.5751/ ES-08748-210341

Folke, C., S. R. Carpenter, B. Walker, M. Scheffer, T. Chapin, and J. Rockström. 2010. Resilience thinking: integrating resilience, adaptability and transformability. Ecology and Society 15(4): 20. [online] URL: http://www.ecologyandsociety.org/vol15/iss4/ art20/ http://dx.doi.org/10.5751/ES-03610-150420

Fordham, M., W. E. Lovekamp, D. S. K. Thomas, and B. D. Phillips. 2013. Understanding social vulnerability. Pages 1-32 in D. S. K. Thomas, B. D. Phillips and W. E. Lovekamp, editors. Social vulnerability to disasters. Taylor and Francis, Boca Raton, Florida, USA.

Gotham, K. F., and R. Campanella. 2013. Constructions of resilience: ethnoracial diversity, inequality, and post-Katrina recovery, the case of New Orleans. Social Sciences 2:298-317. http://dx.doi.org/10.3390/socsci2040298

Gotts, N. M. 2007. Resilience, panarchy, and world-systems analysis. Ecology and Society 12(1): 24. [online] URL: https:// www.ecologyandsociety.org/vol12/iss1/art24/ http://dx.doi.org/10.5751/ ES-02017-120124

Greenhalgh, K., K. M. Meyer, K. M. Aagaard, and P. Wilmes. 2016. The human gut microbiome in health: establishment and resilience of microbiota over a lifetime. Environmental Microbiology 18(7):2103-2116. http://dx.doi.org/10.1111/1462-2920.13318

Gunderson, L. H., C. R. Allen, and C. S. Holling. 2010. Foundation of ecological resilience. Island Press, Washington, D. C., USA.

Gunderson, L., and C. S. Holling. 2002. Panarchy. Island Press, Washington, D.C., USA.

Gunderson, L. H., S. S. Light, and C. S. Holling. 1995. Lessons from the Everglades. Science and Biodiversity Policy 45:66-73. https://doi.org/10.2307/1312447

Harris, L. M., E. K. Chu, and G. Ziervogel. 2017. Negotiated resilience. Resilience 6(3):196-214. https://doi.org/10.1080/21693293.2017.1353196 http://dx.doi.org/10.1080/21693293.2017.1353196

Hobfoll, S. 2011. Conservation of resources theory: its implication for stress, health, and resilience. Pages 127-147 in S. Folkman, editor. The Oxford handbook of stress, health, and coping. Oxford University Press, New York, New York, USA. http://dx.doi.org/10.1093/oxfordhb/9780195375343.013.0007

Holling, C. S. 1973. Resilience and stability of ecological systems. Annual Review of Ecology and Systematics 4(1):1-23. http://dx. doi.org/10.1146/annurev.es.04.110173.000245

Holling, C. S. 1986. The resilience of terrestrial ecosystems: local surprise and global change. Pages 292-317 in W. C. Clark and R. E. Munn, editors. Sustainable development of the biosphere. Cambridge University Press, Cambridge, UK.

Hou, F., and A. Bonikowska. 2016. Educational and labour market outcomes of childhood immigrants by immigration class. Analytical Studies Branch Research Paper Series 377, Catalogue no:11F0019M, Statistics Canada, Ottawa, Ontario, Canada.

Jackley, J., L. Gardner, A. F. Djunaedi, and A. K. Salomon. 2016. Ancient clam gardens, traditional management portfolios, and the resilience of coupled human-ocean systems. Ecology and Society 21(4): 20. https://doi.org/10.5751/ES-08747-210420 http:// dx.doi.org/10.5751/ES-08747-210420

Jackson, S., and T. L. J. Ferris. 2013. Resilience principles for engineered systems. Systems Engineering 16(2):152-164. http:// dx.doi.org/10.1002/sys.21228 
Kalisch, R., M. B. Müller, and O. Tüsher. 2015. A conceptual framework for the neurobiological study of resilience. Behavioral and Brain Science 38:1-21. http://dx.doi.org/10.1017/ S0140525X1400082X

Kofinas, G., D. Clark, and G. K. Hovelsrud. 2013. Adaptive and transformative capacity. Pages 73-93 in Arctic Council. Arctic Resilience Interim Report. Arctic Council, Stockholm Environment Institute and Stockholm Resilience Centre, Stockholm, Sweden.

Kruk, M. E., M. Myers., S. T. Varpilah, and B. T. Dahn. 2015. What is a resilient health system? Lessons from Ebola. The Lancet 385(9980):1910-1912. http://dx.doi.org/10.1016/S0140-6736(15) 60755-3 http://dx.doi.org/10.1016/S0140-6736(15)60755-3

Leichenko, R. 2011. Climate change and urban resilience. Current Opinion in Environmental Sustainability 3(3):164-168. https://doi. org/10.1016/j.cosust.2010.12.014 http://dx.doi.org/10.1016/j. cosust.2010.12.014

Lerner, R. M. 2014. Relational developmental systems theories of positive youth development: methodological issues and implications. Pages 66-94 in P. C. M. Molenaar, R. M. Lerner and K. M. Newell, editors. Handbook of developmental systems theory and methodology. Guilford, New York, New York, USA.

Levin, S. A. 1998. Ecosystems and the biosphere as complex adaptive systems. Ecosystems 1:431-436. https://doi.org/10.1007/ $\underline{\mathrm{s} 100219900037}$ http://dx.doi.org/10.1007/s100219900037

Liew, J., Q. Cao, J. N. Hughes, and M. H. F. Deutz. 2018. Academic resilience despite early academic adversity: a three-wave longitudinal study on regulation-related resiliency, interpersonal relationships, and achievement in first to third grade. Early Education and Development 29(5):762-779. https://doi. org/10.1080/10409289.2018.1429766 http://dx.doi. org/10.1080/10409289.2018.1429766

Lupien, S. J., S. King, M. J. Meaney, and B. S. McEwen. 2001. Can poverty get under your skin? Basal cortisol levels and cognitive function in children from low and high socioeconomic status. Development and Psychopathology 13(3):651-674. http:// dx.doi.org/10.1017/S0954579401003133

Martin, R., P. Sunley, B. Gardiner, and P. Tyler. 2016. How regions react to recessions: resilience and the role of economic structure. Regional Studies 50(4):561-585. http://dx.doi.org/10.1080/0034$\underline{3404.2015 .1136410}$

Masten, A. S. 2011. Resilience in children threatened by extreme adversity: frameworks for research, practice, and translational synergy. Development and psychopathology 23:493-506. http://dx. doi.org/10.1017/S0954579411000198

Masten, A. S. 2014. Global perspectives on resilience in children and youth. Child Development 85(1):6-20. http://dx.doi. org/10.1111/cdev.12205

Naess, A. 1989. Ecology, community and lifestyle: outline of an ecosophy. D. Rothenberg, Translation. Cambridge University Press, Cambridge, UK. http://dx.doi.org/10.1017/CBO9780511525599

Nix, R. L., E. E. Pinderhughes, K. L. Bierman, and J. J. Maples. 2005. Decoupling the relation between risk factors for conduct problems and the receipt of intervention services: participation across multiple components of a prevention program. American Journal of Community Psychology 36(3/4):307-325. https://doi. org/10.1007/s10464-005-8628-9 http://dx.doi.org/10.1007/ s10464-005-8628-9

Norris, F. H., S. P. Stevens, B. Pfefferbaum, K. F. Wyche, and R. L. Pfefferbaum. 2008. Community resilience as a metaphor, theory, set of capacities, and strategy for disaster readiness. American Journal of Community Psychology 41(1-2):127-150. http://dx.doi.org/10.1007/s10464-007-9156-6

Nyborg, K., J. M. Anderies, A. Dannenberg, T. Lindahl, C. Schill, M. Schlüter, W. N. Adger, K. J. Arrow, S. Barrett, S. Carpenter, F. S. Chapin III, A-S. Crépin, G. Daily, P. Ehrlich, C. Folke, W. Jager, N. Kautsky, S. A. Levin, O. J. Madsen, S. Polasky, M. Scheffer, B. Walker, E. U. Weber, J. Wilen, A. Xepapadeas, A. and de Zeeuw. 2016. Social norms as solutions. Science 354(6308):4243. http://dx.doi.org/10.1126/science.aaf8317

Obradovic, J. 2012. How can the study of physiological reactivity contribute to our understanding of adversity and resilience processes in development? Development and Psychopathology 24 (2):371-387. http://dx.doi.org/10.1017/S0954579412000053

Olsson, L., A. Jerneck, H. Thoren, J. Persson, and D. O'Byrne. 2015. Why resilience is unappealing to social science: theoretical and empirical investigations of the scientific use of resilience. Science Advances 1(4): e1400217. [online] URL: http://advances. sciencemag.org/content/1/4/e1400217 http://dx.doi.org/10.1126/ sciadv. 1400217

Ostrom, E. 1990. Governing the commons: the evolution of institutions for collective action. Cambridge University Press, Cambridge, UK. http://dx.doi.org/https://doi.org/10.1017/ CBO9780511807763

Ostrom, E. 2009. A general framework for analyzing sustainability of social-ecological systems. Science 325:419-422. http://dx.doi.org/10.1126/science.1172133

Ott, E., and P. Montgomery. 2015. Interventions to improve the economic self-sufficiency and well-being of resettled refugees: a systematic review. Campbell Systematic Reviews 11, Campbell Collaboration, Oslo, Norway. http://dx.doi.org/10.4073/csr.2015.4

Pahl-Wostl, C. 2009. A conceptual framework for analysing adaptive capacity and multi-level learning processes in resource governance regimes. Global Environmental Change 19(3):354-365. http://dx.doi.org/10.1016/j.gloenvcha.2009.06.001

Panter-Brick, C., and M. Eggerman. 2012. Understanding culture, resilience, and mental health: the production of hope. Pages 369-386 in M. Ungar, editor. The socialecology of resilience: a handbook of theory and practice. Springer, New York, New York, USA. http://dx.doi.org/10.1007/978-1-4614-0586-3 29

Panter-Brick, C., C. Hadfield, R. Dajani, M. Eggerman, A. Ager, and M. Ungar. 2017. Resilience in context: a brief and culturally grounded measure for Syrian refugee and Jordanian hostcommunity adolescents. Child Development 89(5):1803-1820. https://doi.org/10.1111/cdev.12868 http://dx.doi.org/10.1111/cdev.12868

Pfefferbaum, R. L., B. Pfefferbaum, K. Wyche, F. Norris, and D. Reissman. 2006. Community assessment of resilience tool. Terrrorism and Disaster Center of the National Child Traumatic Stress Network, Oklahoma City, Oklahoma, USA. 
Popa, F., M. Guillermin, and T. Dedeurwaerdere. 2015. A pragmatist approach to transdisciplinarity in sustainability research: from complex systems theory to reflexive science. Futures 65:45-56. https://doi.org/10.1016/j.futures.2014.02.002 http:// dx.doi.org/10.1016/j.futures.2014.02.002

Prilleltensky, I., and O. Prilleltensky. 2007. Promoting well-being: linking personal, organizational, and community change. Wiley, New York, New York, USA.

Prince-Embury, S. 2013. Resiliency scales for children and adolescents: theory, research, and clinical application. Pages 1944 in S. Prince-Embury and D. H. Saklofske, editors. Resilience in children, adolescents, and adults: translating research into practice. Springer, New York, New York USA. http://dx.doi. org/10.1007/978-1-4614-4939-3 3

Quinlan, A., M. Berbés-Blázquez, J. L. Haider, and G. D. Peterson. 2016. Measuring and assessing resilience: broadening understanding through multiple disciplinary perspectives. Journal of Applied Ecology 53:677-687. https://doi.org/10.1111/1365-2664.12550 http://dx.doi.org/10.1111/1365-2664.12550

Raglan, G. B., and J. Schulkin. 2014. Introduction to allostasis and allostatic load. Pages 33-43 in M. Kent, M. C. Davis and J. W. Reich, editors. The resilience handbook: approaches to stress and trauma. Routledge, New York, New York, USA.

Resilience Alliance. 2010. Assessing resilience in social-ecological systems: workbook for practitioners. Version 2. [online] URL: http://www.reefresilience.org/pdf/ResilienceAssessment2.pdf

Robards, M. D., M. L. Schoon, C. L. Meek, and N. L. Engle. 2011. The importance of social drivers in the resilient provision of ecosystem services. Global Environmental Change 21(2):522529. https://doi.org/10.1016/j.gloenvcha.2010.12.004 http://dx. doi.org/10.1016/j.gloenvcha.2010.12.004

Rocha, J. C., G. D. Peterson, and R. Biggs. 2015. Regime shifts in the anthropocene: drivers, risks, and resilience. PLoS One 10 (8):1-16. https://doi.org/10.1371/journal.pone.0134639

Ruhl, J. B. 2011. General design principles for resilience and adaptive capacity in legal systems-with application to climate change adaptation. North Carolina Law Review 89:1373-1404. [online] URL: http://scholarship.law.unc.edu/nclr/vol89/iss5/3

Rutter, M. 1987. Psychosocial resilience and protective mechanisms. American Journal of Orthopsychiatry 57:316-331. https://doi.org/10.1111/j.1939-0025.1987.tb03541.x http://dx.doi. org/10.1111/j.1939-0025.1987.tb03541.x

Saini, M., and A. Shlonsky. 2012. Systematic synthesis of qualitative research. Oxford University Press, New York, New York, USA. http://dx.doi.org/https://doi.org/10.1093/acprof: oso/9780195387216.001.0001

Salat, S., and L. Bourdic. 2012. Systemic resilience of complex urban systems. Journal of Land Use, Mobility and Environment 5 (2):55-68. http://dx.doi.org/10.6092/1970-9870/918

Schlüter, M., R. Biggs, M. L. Schoon, M. D. Robards, and J. M. Anderies. 2015. Reflections on building resilience - interactions among principles and implications for governance. Pages 251-282 in R. Biggs, M. Schlüter, and M. L. Schoon, editors. Principles for building resilience: sustaining ecosystem services in social- ecological systems. Cambridge University Press, Cambridge, UK. http://dx.doi.org/https://doi.org/10.1017/CBO9781316014240.011

Snilstveit, B., S. Oliver, and M. Vojtkova. 2012. Narrative approaches to systematic review and synthesis of evidence for international development policy and practice. Journal of Development Effectiveness 4(3):409-429. https://doi. org/10.1080/19439342.2012.710641 http://dx.doi. org/10.1080/19439342.2012.710641

Southwick, S. M., G. A. Bonanno, A. S. Masten, C. Panter-Brick, and R. Yehuda. 2014a. Resilience definitions, theory, and challenges: interdisciplinary perspectives. European Journal of Psychotraumatology 5(1):25338-25414. https://doi.org/10.3402/ ejpt.v5.25338

Southwick, S. M., H. Douglas-Palumberi, and R. H. Pietrzak. 2014b. Resilience. Pages 590-606 in M. J. Friedman, T. M. Keane and P. A. Resnick, editors. Handbook of PTSD: science and practice. Second edition. Guilford, New York, New York, USA.

Sterbenz, J. P. G., D. Hutchison, E. K. Çetinkaya, A. Jabbar, J. P. Rohrer, M. Schöller, and P. Smith. 2010. Resilience and survivability in communication networks: strategies, principles, and survey of disciplines. Computer Networks 54(8):1245-1265. http://dx.doi.org/10.1016/j.comnet.2010.03.005

Tengö, M., E. S. Brondizio, T. Elmqvist, P. Malmer, and M. Spierenburg. 2014. Connecting diverse knowledge systems for enhanced ecosystem governance: the multiple evidence base approach. AMBIO 43(5): 579. https://doi.org/10.1007/ s13280-014-0501-3 http://dx.doi.org/10.1007/s13280-014-0501-3

Theron, L. C. 2015. Toward a culturally and contextually sensitive understanding of resilience: privileging the voices of black, South African young people. Journal of Adolescent Research 31(6):635670. https://doi.org/10.1177/0743558415600072 http://dx.doi. org/10.1177/0743558415600072

Thomas, J., and A. Harden. 2008. Methods for the thematic synthesis of qualitative research in systematic reviews. $B M C$ Medical Research Methodology 8: 45. https://doi.

org/10.1186/1471-2288-8-45 http://dx.doi.org/10.1186/1471-2288-8-45

Thomas, J., A. Harden, and M. Newman. 2012. Synthesis: combining results systematically and appropriately. Pages 179 226 in D. Gough, S. Oliver, and J. Thomas, editors. An introduction to systematic reviews. Sage Publications, London, UK.

Ungar, M. 2004. A constructionist discourse on resilience: multiple contexts, multiple realities among at-risk children and youth. Youth and Society 35(3):341-365. https://doi. org/10.1177/0044118X03257030 http://dx.doi.org/10.1177/0044$\underline{118 \times 03257030}$

Ungar, M. 2008. Resilience across cultures. The British Journal of Social Work 38(2):218-235. https://doi.org/10.1093/bjsw/bcl343 http:// dx.doi.org/10.1093/bjsw/bcl343

Ungar, M. 2011. The social ecology of resilience: addressing contextual and cultural ambiguity of a nascent construct. American Journal of Orthopsychiatry 81(1):1-17. https://doi. org/10.1111/j.1939-0025.2010.01067.x http://dx.doi.org/10.1111/ j.1939-0025.2010.01067.x

Ungar, M. 2015a. Practitioner review: diagnosing childhood resilience - a systemic approach to the diagnosis of adaptation in 
adverse social and physical ecologies. The Journal of Child Psychology and Psychiatry 56(1):4-17. https://doi.org/10.1111/ jepp. 12306

Ungar, M. 2015b. Social ecological complexity and resilience processes. Commentary on "A conceptual framework for the neurobiological study of resilience." Behavioral and Brain Sciences 38:50-51. https://doi.org/10.1017/S0140525X14001721

Ungar, M. 2015c. Varied patterns of family resilience in challenging contexts. Journal of Marital and Family Therapy 42 (1):19-31. http://dx.doi.org/https://doi.org/10.1111/jmft.12124

Ungar, M. 2016. Which counts more? The differential impact of the environment or the differential susceptibility of the individual? The British Journal of Social Work 47(5):1279-1289. https://doi.org/10.1093/bjsw/bcw109

United Nations International Strategy for Disaster Reduction (UNISDR). 2009. UNISDR terminology for disaster risk reduction. UNISDR-20-2009-Geneva. [online] URL: http:// www.unisdr.org/files/7817_UNISDRTerminologyEnglish.pdf

Usdin, L. 2014. Building resiliency and supporting distributive leadership post-disaster. International Journal of Leadership in Public Services 10(3):157-171. https://doi.org/10.1108/ IJLPS-07-2014-0010 http://dx.doi.org/10.1108/IJLPS-07-2014-0010

Vaillant, G. E. 2015. Resilience and posttraumatic growth. Pages 45-70 in D. V. Jeste and B. W. Palmer, editors. Positive psychiatry: a clinical handbook. American Psychiatric Association Publishing, Washington, D.C., USA. http://dx.doi.org/10.1176/ appi.books.9781615370818.dj03

van Hal, J. D. M. 2014. Energiezuinig financieren: ESCo's als financiële propositie. Pages 157-200 in T. M. Berkhout and A. A. van Velten, editors. Perspectieven voor vastgoedfinanciering. Stichting Fundatie Bachiene, Amsterdam, The Netherlands.

Vygotsky, L. S. 1978. Mind in society: the development of higher psychological processes. M. Cole, V. John-Steiner, S. Scribner and E. Souberman, editors. Harvard University Press, Cambridge, Massachusetts, USA.

Walker, B. H., and J. A. Meyers. 2004. Thresholds in ecological and social-ecological systems: a developing database. Ecology and Society 9(2): 3. [online] URL: https://www.ecologyandsociety. org/vo19/iss2/art3/

Walker, B. H., and D. Salt. 2012. Resilience practice: building capacity to absorb disturbance and maintain function. Island Press, Washington, D.C., USA. http://dx.doi.org/https://doi. org/10.5822/978-1-61091-231-0

Walsh, F. 2016. Family resilience: a developmental systems framework. European Journal of Developmental Psychology 13 (3):313-324. https://doi.org/10.1080/17405629.2016.1154035 http:// dx.doi.org/10.1080/17405629.2016.1154035

Wardekker, J. A., A. de Jong, J. M. Knoop, and J. P. van der Sluijs. 2010. Operationalising a resilience approach to adapting an urban delta to uncertain climate changes. Technological Forecasting and Social Change 77(6):987-998. http://dx.doi.org/10.1016/j. techfore.2009.11.005
Wessells, M. G. 2015. Bottom-up approaches to strengthening child protection systems: placing children, families, and communities at the center. Child Abuse and Neglect 43:8-21. https://doi.org/10.1016/j.chiabu.2015.04.006 http://dx.doi.org/10.1016/ j.chiabu.2015.04.006

Xu, L., and Y. Kajikawa. 2017. An integrated framework for resilience research: a systematic review based on citation network analysis. Sustainability Science 13(1):235-254. https://doi. org/10.1007/s11625-017-0487-4 http://dx.doi.org/10.1007/ $\underline{\text { s11625-017-0487-4 }}$

Xue, X., L. Wang, and R. J. Yang. 2018. Exploring the science of resilience: critical review and bibliometric analysis. Natural Hazards 90(1):477-510. https://doi.org/10.1007/s11069-017-3040$\mathrm{y} \underline{\mathrm{http}} / / / \mathrm{dx}$.doi.org/10.1007/s11069-017-3040-y

Zolli, A. 2012. Resilience: why things bounce back. Simon and Schuster, Toronto, Ontario, Canada. 